алюминия слегка увеличивают прочностные характеристики и немного увеличивают пористость. В целом, добавки алюминия не влияли на форму пор. В образцах, где алюминий не прореагировал, можно наблюдать зародыши пор возле частиц алюминия.

\section{4. Вывод}

При ходе процесса изготовления влияние области температур формирования и создания структуры напрямую зависит от качества стекла для изготовления пеностекла, что определяется физико-химическими свойствами.

Увеличение локального влагосодержания не влечет за собой локального увеличения пор исходной смеси. При большом содержании примесей в материале при вспучивании образуется система пластов из пор. Большое влияние на пористость играет исходный состав смеси, влажность материала, время термической обработки и температура, при которой она происходит.

Проанализировав весь эксперимент, можно сделать вывод, что градиент температур также влияет на пористость. При сильно высокой температуре может произойти усадка материала.

\section{Литература}

1. Чейлытко, А. А. Экспериментальные исследования теплофизических характеристик пористого дисперсного материала в зависимости от различных режимов термообработки [Текст] / А. А. Чейлытко // Восточно-Европейский журнал передовых технологий. - 2009. - № 5/6(41). - С. 4-7.

2. Чейлытко, А. О. Исследование влияния пор на теплопроводность материалов [Текст] / А. О. Чейлытко // Технологический аудит и резервы производства. - 2013. - Т. 2, № 2(10). - C. 14-17.

3. Демидович, Б. К. Производство и применение пеностекла [Текст] / Б. К. Демидович. - Минск: Наука и техника, 1972. -304 c.
4. Чудновский, А. Ф. Теплофизические характеристики дисперсных материалов [Текст] / А. Ф. Чудновский. - М. Государственное издательство физико-математической литературы, 1962. - 456 с.

5. Нагёy, W. J. Amer. Chem. Soc [Text] / W. Нагёy. - 1935. № 1. - P. 127

6. Павленко, А. М. Создание основы для нового теплоизоляционного материала [Текст] / А. М. Павленко, А. А. Чейлытко // Восточно-Европейский журнал передовых технологий. 2009. - № 39. - С. 13-16.

7. Садченко, Н. П. Исследование в области получения пеностекла для низкотемпературной изоляции [Текст] : автореф. канд. дисс. / Н. П. Садченко. - Минск, 1973.

8. Лыков, А. В. Теория сушки [Текст] / А. В. Лыков. - М «Энергия»,1968. - 472 с.

9. ГОСТ Р 28874-2004. Огнеупоры. Классификация [Текст]. Введ. 2006-01-01. - М.: Изд-во стандартов, 2001. - 20 с.

10. ГОСТ Р 24748-2003. Изделия известково-кремнеземистые теплоизоляционные. Технические условия [Текст]. Введ. 2004-03-01. - М.: Изд-во стандартов, 2003. - 8 с.

\section{ДОСЛІДЖЕННЯ ФОРМУВАННЯ ЛОР У ВСПУЧУЮЩОМУ МАТЕРІАЛ!}

У роботі представлено експериментальні дослідження формування пор у гідросилікатах. Наведено загальні закономірності розвитку пористої структури у піномасі з різними хімічними складовими. Зроблені загальні висновки про вплив домішок і зміни локального вологовмісту у вихідній масі на процес спучування матеріалу.

Ключові слова: пористість, структура матеріалу, теплоізоляційний матеріал, спучування.

Чейлытко Андрей Александрович, кандидат технических наук, доцент, кафедра теплоэнергетики, Запорожская государственная инженерная академия, Украина, e-mail: cheylitko@ya.ru.

Чейлитко Андрій Олександрович, кандидат технічних наук, доцент, кафедра теплоенергетики, Запорізька державна інженерна академія, Украӥна.

Cheylitko Andriy, Zaporizhia State Engineering Academy, Ukraine, e-mail: cheylitko@ya.ru

УДК 674.08

Завинский С. и. ТЕОРЕТИЧЕСКИЙ ПОДХОД К ОПИСАНИЮ
ПРОЦЕССА ЭКСТРУЗИИ КОМПОЗИТНОГО
ОРГАНКЧЕСКОГО СЫРЬЯ

Рассмотрен вопрос формирования теоретического подхода к описанию движения композитного органического сырья в предматричной зоне экструдера. В качестве основы для этого принято описание движения жидкости в коаксиальном конфузоре, которое необходимо дополнить сведениями о реологических характеристиках сырья с учетом тепловых эффектов.

Ключевые слова: композитное органическое сырье, предматричная зона, коаксиальный конфузор, одношнековый экструдер.

\section{1. Введение}

Проектирование оптимальных конструкций аппаратов химической промышленности - одна из наиболее актуальных задач, от решения которой в значительной степени зависит эффективность технологических процессов. Основные принципы проектирования и расчета элементов такого оборудования изложены в ряде научных работ последних лет. Например, в работах [1-4] подробно исследованы роторные аппараты и процессы мокрого улавливания пыли в аппаратах такого типа, а также эффективность этих процессов в зависимости от конструктивных параметров. Шнековые экструдеры в силу своей предназначенности для переработки органического сырья также могут быть отнесены к аппаратам химической промышленности и, соответственно, должны исследоваться на предмет возможной оптимизации их конструкций с целью повышения эффективности 
реализуемых в них технологических процессов. Применение шнековых экструдеров для переработки композитного органического сырья становится все более актуальным вопросом в химической промышленности. Актуальность исследования экструдеров подтверждает большое количество публикаций и патентов, многие из которых направлены на аспекты практического применения экструдеров и на процессы преобразования материала в экструдере.

В настоящее время экструдеры применяются не только в традиционных технологиях переработки полимеров, но и все шире в технологиях получения композитных материалов или переработки композитного органического сырья. В качестве примеров можно привести древеснополимерные композитные материалы (ДПК), топливные брикеты [5-7], экструдированные комбикорма [8] и пищевые продукты, биоразлагаемые полимерные изделия, органо-минеральные удобрения с контролируемым высвобождением питательных компонентов.

В указанных технологиях распространены одно- и двухшнековые экструдеры. Двухшнековые экструдеры обладают более широкими технологическими возможностями [9] при организации различных функциональных зон по длине шнекового канала с различной температурой и давлением, подводом и отводом продуктов химических реакций, тепла, с различным градиентом сдвига и т. д., имеют более широкие возможности автоматизации и регулирования. В то же время одношнековые экструдеры имеют более простую конструкцию, и большую производительность, а также позволяют получить более высокую удельную энергонапряженность процессов, особенно в предматричной зоне.

Анализ конструкции одношнекового экструдера, имеющего различные функциональные зоны (транспортную, нагрева, гомогенизации, сжатия, уплотнения, разуплотнения и т. д.) [10], показывает, что наиболее глубокие изменения структуры материала происходят в предматричной зоне, где обычно наблюдаются самые высокие температуры, давления, и градиенты сдвига.

В предматричной зоне экструдера материал, как правило, переходит в вязко-пластичное состояние и его движение, можно рассматривать как ползущее течение неньютоновской жидкости в соосном коническом конфузоре, образованном поверхностью матрицы и корпусом шнека.

Целью настоящей работы является формирование теоретического подхода к исследованию предматричной зоны экструдера при переработке композитного органического сырья.

Основными задачами для достижения поставленной цели являются: обзор известных работ, математическая формулировка задачи, анализ полученного решения и постановка задач дальнейшего теоретического исследования.

\section{2. Обзор ранних работ}

Систематического исследования ползущего течения в соосных конических конфузорах до настоящего времени не было. В работе [11] предлагается использовать для расчета течений в любых соосных кольцевых каналах переменного сечения ступенчатую аппроксимацию отрезками кольцевых прямолинейных труб. Данное предложение можно отнести и к соосным коническим конфузорам, хотя данная методика авторами работ пред- лагалась для диффузорного течения, но при таком подходе сходящиеся течения заменяются прямолинейными, что может привести к значительным погрешностям, особенно в случае больших значений углов раскрытия граничных поверхностей.

В работе [12] приведено выражение для расчета перепада давления в сужающемся зазоре межу двумя коническими поверхностями, но без объяснения входящих в него параметров. Автором в работе [13] сделан краткий анализ распределения скорости и давления в соосном коническом конфузоре с общей вершиной границ.

\section{3. Математическая формулировка задачи}

Наиболее системными и исчерпывающими являются постановка и решение задачи о ползущем течении в соосном коническом конфузоре с общей вершиной границ, приведенная в [14].

Были приняты следующие обозначения (рис. 1):

$$
\begin{aligned}
& t=\frac{T}{h_{0}}=\xi_{1}-\xi ; \quad \xi=\frac{R}{h_{0}} ; \quad v=\frac{V}{V_{0}} ; \\
& \Pi=\frac{\left(P-P_{0}\right) h_{0}}{\mu V_{0}} ; \quad \tau=\cos \theta ; \quad \operatorname{Re}_{1}=\frac{\rho h_{0} V_{0}}{\mu},
\end{aligned}
$$

где $h_{0}$ - линейный масштабный множитель, использующийся для обезразмеривания переменных в уравнениях движения жидкости, в дальнейшем величина $h_{0}$ будет идентифицирована как ширина канала на выходе, $\xi=\frac{R_{1}}{h_{0}}-$ безразмерная координата входа в канал, $V_{0}-$ средняя по площади поверхности поперечного сечения входа в канал скорость жидкости, которая определяется выражением:

$$
V_{0}=\frac{Q}{S_{1}}
$$

где $S_{1}-$ площадь поперечного сечения канала координатной поверхностью на его входе:

$$
S_{1}=2 \pi R_{1}^{2}\left(\cos \theta_{1}-\cos \theta_{2}\right)
$$

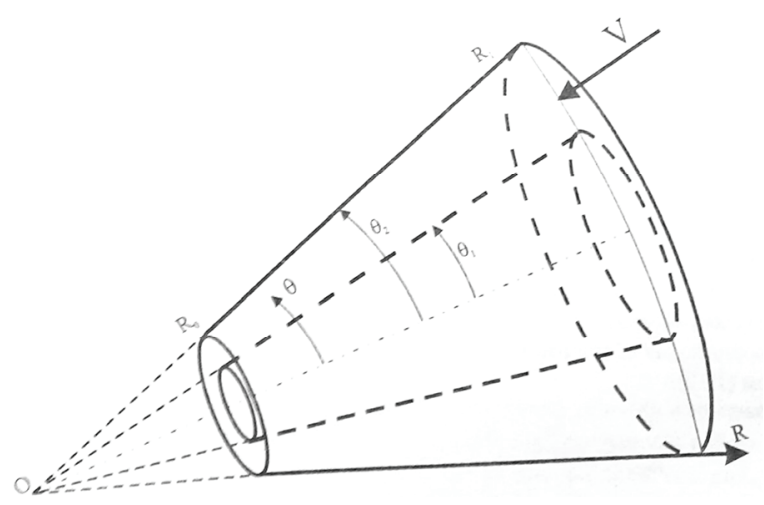

Pис. 1. Геометрия соосного конического конфузора с общей вершиной границ: $\square$ - вершина границ, она же полюс сферической системы координат; $R$ - радиальная сферичесая координата; $R_{0}$ радиальная координата выхода из конфузора; $R_{1}$ - радиальная координата входа в конфузор; $V$ - скорость жидкости; $\theta-$ азимутальная сферическая поверхности; $\theta_{1}, \theta_{2}$ полууглы раскрытин внутренней и внешней границ канала 
В результате получено аналитическое решение вида:

$$
\bar{\Pi}(t)=\frac{\lambda_{C}+6 \xi_{1}^{2}}{3 \xi_{1}^{3}}\left[1-\left(\frac{\xi_{1}}{\xi_{1}-t}\right)^{3}\right] .
$$

Данное решение позволяет определить одну из основных характеристик течения в предматричной зоне гидравлические потери, преодоление которых происходит за счет шнекового нагнетателя. Следовательно мы получили исходные данные для его расчета.

Описание движения реального композитного сырья осложняется существенным влиянием температуры и градиента сдвига на вязкость жидкости. Поэтому уравнение (4) необходимо дополнить сведениями о реологических характеристиках сырья, а также уравнением теплового баланса.

Кроме того, градиент сдвига внутри потока при движении сырья в предматричной зоне возникает не только при его движении между поверхностью матрицы и корпуса шнека, но и за счет относительного движения (поворота) корпуса шнека и матрицы. Возникающий при этом сдвиг существенно изменит эффективную вязкость сырья, а значит и распределение давлений в предматричной зоне.

Граничные условия потока на стенках матрицы и корпуса шнека в реальности могут отличаться от принятых нами условий «прилипания» потока к стенкам, и в то же время искусственно создавая условия для сцепления сырья и границ потока, можно влиять на градиент сдвига внутри потока и опять же на распределение давлений в предматричной зоне.

\section{4. Выводы}

В рамках принятого теоретического подхода дальнейшие теоретические и практические исследования должны иметь следующие направления:

- определение реологических характеристик конкретных видов сырья, подлежащего переработке в экструдере;

- определение граничных условий, реально имеющихся в потоке в предматричной зоне и разработка конструктивных мероприятий, обеспечивающих целенаправленное управление ими;

- провести учет тепловых эффектов при движении композитного органического сырья в предматричной зоне.

\section{Литература}

1. Питак, И. В. Основы теории и расчета деталей роторного аппарата [Текст] / И. В. Питак // Восточно-Европейский журнал передовых технологий. - 2012. - № 4/7(58). C. $14-17$.

2. Питак, И. В. Определение основных параметров роторного аппарата [Текст] / И. В. Питак, В. Ф. Моисеев, П. В. Кузнєцов // Вестник Национального технического университета «ХПИ».-2012. - № 39. - С. 60-68.

3. Питак, И. В. Исследование процесса мокрого улавливания пыли в роторном вихревом аппарате [Текст] / И. В. Питак // Вестник Национального технического университета «ХПИ». $-2010 .-$ № 17. - С. 135-140.

4. Питак, И. В. Положительные аспекты работы роторного вихревого аппарата на промышленных предприятиях [Текст]
/ И. В. Питак, В. Ф. Моисеев // Вестник Национального технического университета «ХПИ». - 2009. - № 15. C. $9-13$.

5. Трошин, А. Г. Развитие процессов и оборудование для производства топливных брикетов из биомассы [Текст] / А. Г. Трошин, В. Ф. Моисеев, И. А. Тельнов, С. И. Завинский // Восточно-Европейский журнал передовых технологий. - 2010. - № 3/8(45). - С. 36-40.

6. Тельнов, И. А Исследование кинетики сушки опилок и сружки в интенсивном режиме [Текст] / И. А. Тельнов, С. И. Завинский, А. Г. Трошин, В. Ф. Моисеев // Вестник НТУ «ХПИ».2012. - № 10. - С. 139-144.

7. Завинский, С. И. Влияние давления прессования и температуры на свойства брикетов из древесной стружки [Текст] / С. И. Завинский, И. А. Тельнов, А. Г. Трошин, В. Ф. Моисеев // Вестник НТУ «ХПИ». - 2012. - № 10. - С. 144-149.

8. Афанасьев, В. А. Научно-практические основы тепловой обработки зерновых компонентов в технологии комбикормов [Текст] : дис. / В. А. Афанасьев. - Москва, 2003. - 517 с.

9. Kohlgrüber, K. Der gleichläufige Doppelschnecken-extruder [Text] / K. Kohlgrüber. - München, 2007. - 373 p.

10. Завинский, С. И. Исследование предматричной зоны в процессе экструдирования композитного органического сырья [Текст] / С. И. Завинский, И. А. Тельнов, А. Г. Трошин // XXI международная научно-практическая конференция, Ч. III «Інформаційні технологіі». - Харьков, 2013. - С. 16.

11. Хан, Ч. Д. Реология в процессах переработки полимеров [Текст] / Ч. Д. Хан. - М.: Химия, 1979. - 368 с.

12. Рогов, Б. В. Уравнения вязких течений в гладких каналах переменного сечения [Текст] / Б. В. Рогов, И. А. Соколова // Доклады РАН. - 1995. - Т. 345, № 5. - С. 615-618.

13. Панов, А. К. Гидродинамика потоков аномально-вязких нелинейных систем в формующих каналах [Текст] / А. К. Панов, А. Р. Анасов. - Уфа : Гос. нефт. техн. ун-т, 1994. -258 с.

14. Ульев, Л. М. Ламинарные течения в соосных конических каналах $[$ Текст] : монография / Л. М. Ульев. - Т. 1. - Х.: НТУ «ХПИ», 2006. -660 c.

\section{ТЕОРЕТИЧНИЙ ПІДХІД ДО ОПИСУ ПРОЦЕСУ ЕКСТРУЗІї КОМПОЗИТНОї ОРГАНІЧНОї СИРОВИНИ}

Розглянуто питання формування теоретичного підходу до опису руху композитної органічної сировини в предматричній зоні екструдера. В якості основи для цього прийнято опис руху рідини в коаксіальному конфузорі, яке необхідно доповнити відомостями про реологічні характеристики сировини 3 урахуванням теплових ефектів.

Ключові слова: композитна органічна сировина, предматрична зона, коаксіальний конфузор, одношнековий екструдер.

Завинсий Сергей Иванович, аспирант, кафедра интегрированных технологий, процессов и аппаратов, Национальный технический университет «Харьковский политехнический институт», Украина, e-mail: s.zawinskiy@bigmir.net.

Завінський Сергій Іванович, аспірант, кафедра інтегрованих технологій, процесів та апаратів, Національний технічний університет «Харківський політехнічний інститут», Україна.

Zavinskyi Serhii, National Technical University «Kharkiv Polytechnic Institute»,Ukraine, e-mail: s.zawinskiy@bigmir.net 